\title{
First Malaysia uniportal video-assisted thoracic surgery (VATS) masterclass
}

\author{
Diego Gonzalez-Rivas ${ }^{1,2}$, Sivakumar Krishnasamy ${ }^{3}$, Godwin Lew ${ }^{4}$, Ariel Zhu ${ }^{4}$ \\ ${ }^{1}$ Department of Thoracic Surgery, Coruña University Hospital and Minimally Invasive Thoracic Surgery Unit (UCTMI), Coruña, Spain; ${ }^{2}$ Department of \\ Thoracic Surgery, Shanghai Pulmonary Hospital, Tongji University School of Medicine, Shanghai 200000, China; ${ }^{3}$ Department of Cardiothoracic Surgery, \\ University Malaya, Kuala Lumpur, Malaysia; ${ }^{4}$ Fengh Academy of Minimally Invasive Surgery, Fengh Medical Co., Ltd., Shanghai 200000, China \\ Correspondence to: Ariel Zhu. Rm1101, No. 5,968 Jinzhong Rd., Shanghai 200000, China. Email: aph.obd@fenghmedical.com.
}

\begin{abstract}
This is a report of the first Malaysia uniportal VATS masterclass. Directed by Dr. Diego Gonzalez Rivas, co-directed by Dr. Sivakumar Krishnasamy, the 2-day educational program was successfully held in University of Malaya Medical Centre (UMMC). Live surgery and lectures were performed in collaboration between Dr. Diego Gonzalez-Rivas and the Thoracic/Pulmonary Team at UMMC Hospital in Malaysia. Such experience will pave the way for more thoracic surgeons to embrace the newest of the lessinvasive thoracic surgical techniques in Malaysia.
\end{abstract}

Keywords: Uniportal video-assisted thoracic surgery (uniportal VATS); masterclass; Malaysia

Received: 21 August 2019; Accepted: 09 December 2019; Published: 05 July 2020.

doi: $10.21037 /$ jovs.2019.12.10

View this article at: http://dx.doi.org/10.21037/jovs.2019.12.10

\section{Introduction}

"There is good news for lung cancer patients in Malaysia as a new technology for lung cancer surgery is now available at University of Malaya Medical Centre (UMMC) and University of Malaya Specialist Centre (UMSC), offering them painless, cost-effective and shorter hospital stay", reported by BernamaTechnology/Malaysian National News, in Kuala Lumpur, Malaysia on August 6, 2019.

Along with the leadership of Dr. Diego Gonzalez-Rivas, Dr. Sivakumar Krishnasamy enthusiastically agreed to coordinate the course (Figure 1). After days of intense preparation, the first Malaysia uniportal video-assisted thoracic surgery (VATS) masterclass was successfully held in UMMC, the oldest and the No.1 teaching hospital in Malaysia, on August 6-7. Live surgeries with four complex cases were conducted during the This would become the first hands on course of uniportal VATS held in Malaysia and a major milestone of introducing this new technique in Malaysia (Video 1).

\section{About the masterclass}

Directed by Dr. Diego Gonzalez Rivas, co-directed by Dr.

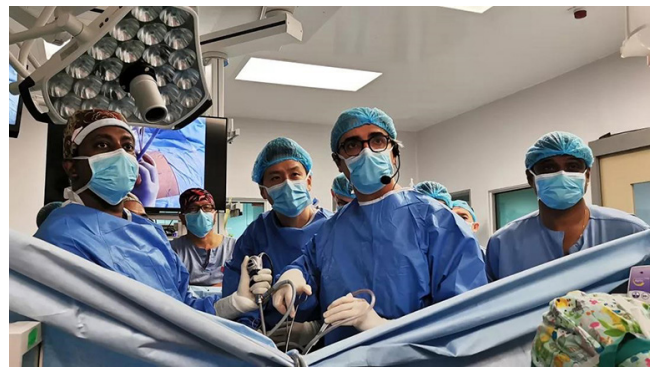

Figure 1 Dr. Diego Gonzalez Rivas and Dr. Sivakumar Krishnasamy during the live surgery session.

Sivakumar Krishnasamy, the 2-day program attracted the Malaysian thoracic community throughout the country. Dr. Diego, the creator and a global educator of uniportal VATS, demonstrated once again his proven leadership in this innovative technique. Intensive live surgeries were successfully performed by Dr. Diego during the masterclass, which was climaxed by his skillful mastery on the four extremely challenging cases. Also, all the participants have shown their tremendous interest in Uniportal technique and Fengh stapling devices. 


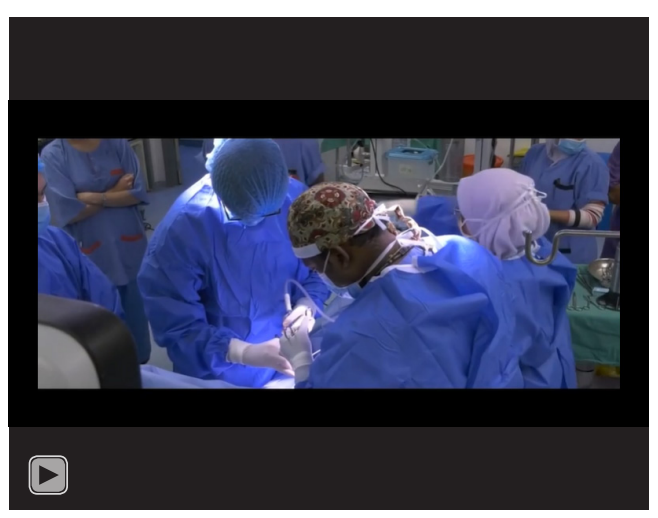

Video 1 Video documentation of the live surgery during the masterclass (1).

\section{The significance of masterclass towards the spread of new technique}

Appealing as it is, the new technique is also demanding, revealing the great need for hands on teaching and continuous training. A well organized and structured program that has been running at the Shanghai Pulmonary Hospital for more than 6 years under the inspirational guidance of Dr. Diego has undoubtedly skyrocketed the technique's adoption worldwide. Of equal significance towards the spread of the technique have proved to be the masterclasses across the world in different countries.

\section{Live surgery session}

The 2-day intensive live surgeries were performed by Dr. Diego, for the purpose of demonstrating the Uniportal approach and the strategies for handling complex cases (Figure 2). More than 30 participants had a valuable experience in observing the live surgery and discussing on these cases.

\section{Four challenging cases were successfully performed through uniportal approach}

Uniportal VATS anatomic left S4-5+1-2C in a complex metastatic lesion involving fissure, uniportal VATS middle lobectomy and repair of a distal huge hole on left main bronchus due to an iatrogenic rupture during intubation, bilateral subxiphoid resection in obese patient and strong adhesions and extremely difficult redo surgery: bilobectomy in a central tumor after chemotherapy (Figure 3).

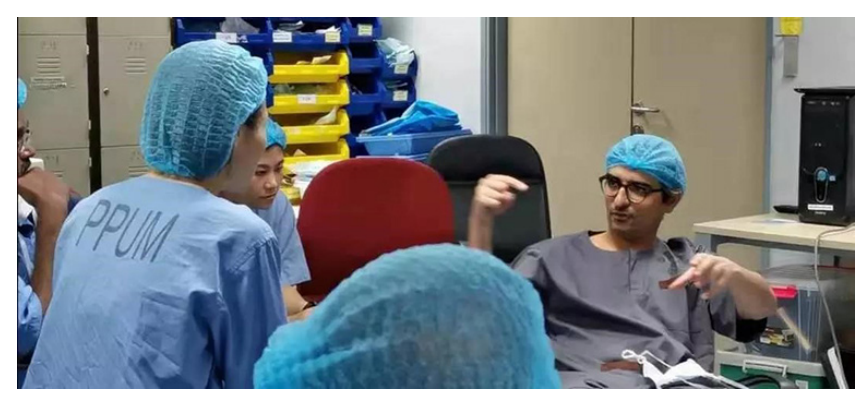

Figure 2 Dr. Diego Gonzalez Rivas with participants during the case discussion.

\section{Unique case by uniportal VATS (Video 2)}

A patient with a $4-\mathrm{cm}$ adenocarcinoma located on the middle lobe was operated by uniportal VATS. During the surgery several bubbles were seen coming from hilum as well as a huge emphysema on the anterior and posterior mediastinum. After the middle lobectomy a systematic lymph node dissection was performed. The initial suspect was an iatrogenic tracheal rupture but after the paratracheal lymph node dissection it was ruled out. During a subcarinal lymph node dissection a huge hole was detected on the left main bronchus, affecting the membranous portion till the secondary carinal division. After a careful exposure of left main bronchus, a direct repair was performed by using a running $3 / 0$ prolene suture. The postoperative course of the patient was uneventful and the chest tube was removed on the $3 \mathrm{rd}$ postoperative day.

\section{Lecture session}

\section{Topic_-Uniportal VATS—-the Past, Present and the Future"}

Dr. Diego started to introduce the innovation of uniportal VATS technique by inspiring stories (Figure 4). Also shared were his extensive global teaching experience in more than 130 countries, which has been significantly influenced numerous places and surgeons around the world. Interesting and insightful lectures were given by several Malaysian leading thoracic surgeons (Figure 5).

\section{Memorandum of Understanding (MoU) signing ceremony (Figures 6,7)}

"Through this MoU, Dr. Diego who is also the creator of the uniportal VATS technique will share his experience to create 


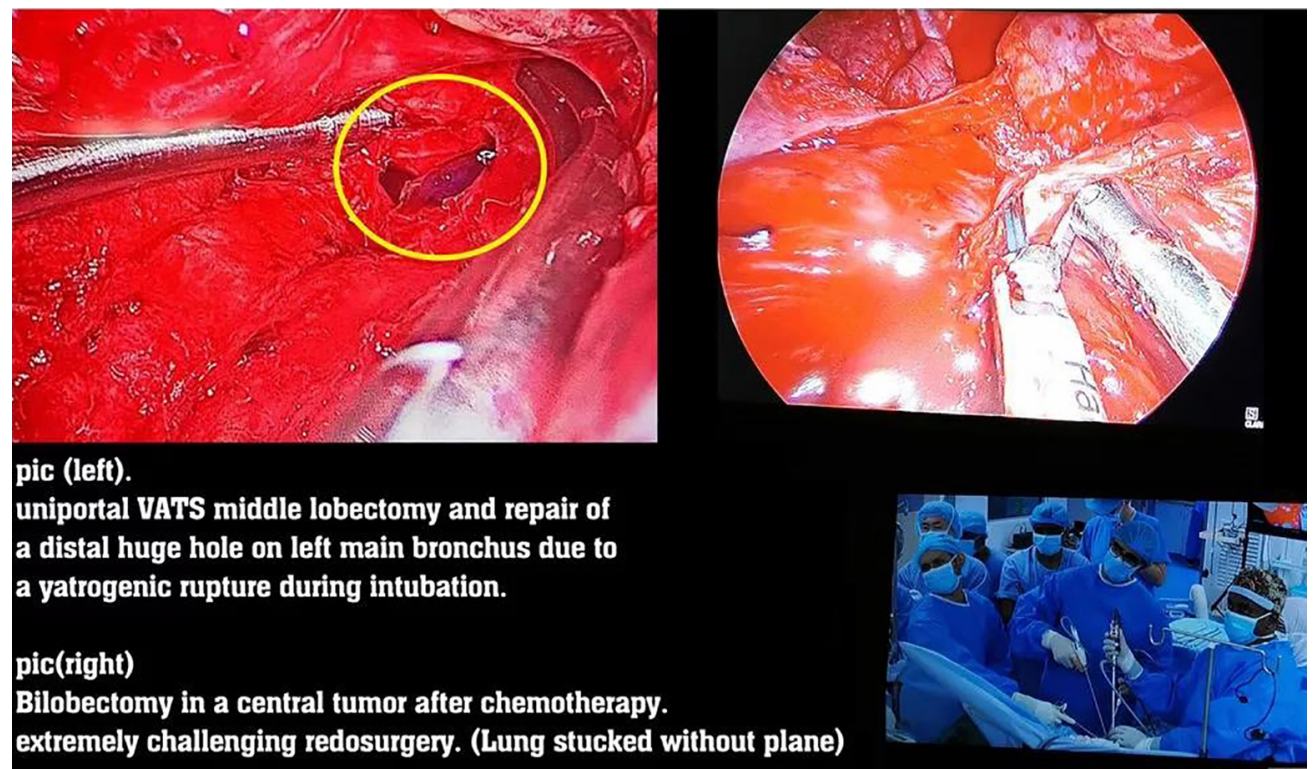

Figure 3 Two complex cases during this masterclass.

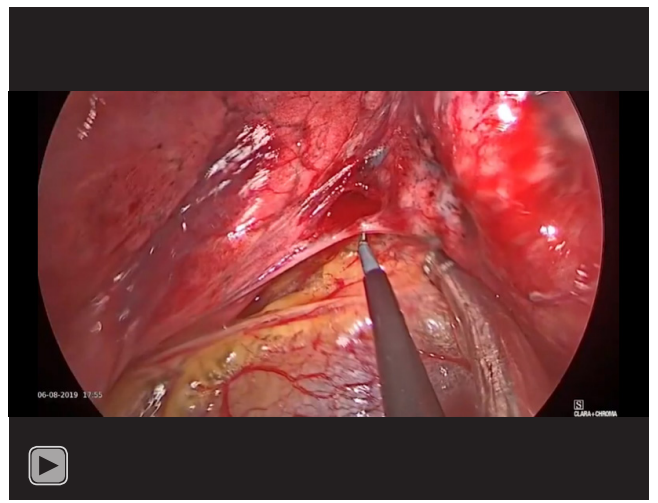

Video 2 Iatrogenic left main bronchus rupture after intubation repaired by uniportal VATS (2). VATS, video-assisted thoracic surgery.

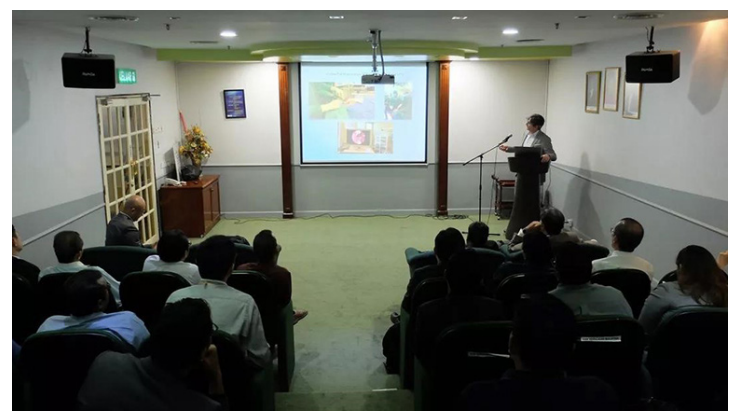

Figure 4 Dr. Diego and participants from Malaysian thoracic society. awareness of this procedure in our country and at the same time to refine the technique to all other surgeons through a short master class", Dr. Sivakumar Krishnasamy talked about the long-term dedication to this new technique education for Malaysian thoracic surgeon community. Fengh Medical is honored to be the exclusive provider of Surgical Stapling Devices for the Masterclass of uniportal VATS.

\section{Fengh Academy of Minimally Invasive Surgery (FAMIS)}

As a leading Chinese enterprise in MIS industry, Fengh Medical initiated a global educational tour program in the beginning of 2019 (Figures 8,9). The great success of the first Malaysia uniportal VATS masterclass will be an educational program model for the long-term planning and organization of the global educational programs of Fengh Medical.

Fengh Medical has been taking the mission of truly contribute to the global MIS community, by providing the surgeon community, especially the young surgeons, with more opportunities to approach the leading experts, cutting-edge techniques and more educational resources. 

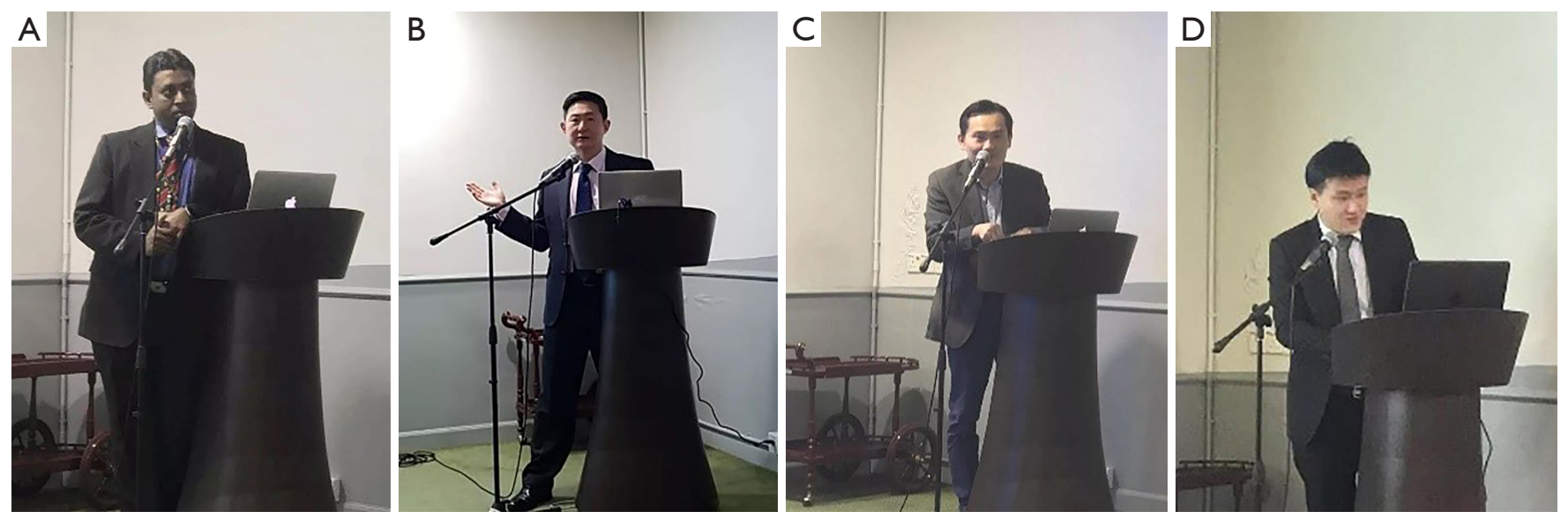

Figure 5 Guest speakers from Malaysian Thoracic Society. Dr. Sivakumar Krishnasamy, Dr. Adrian Ooi Seng Wae, Dr. Soon Sing Yang, Dr. Tan Y. Sheng (from left to right).

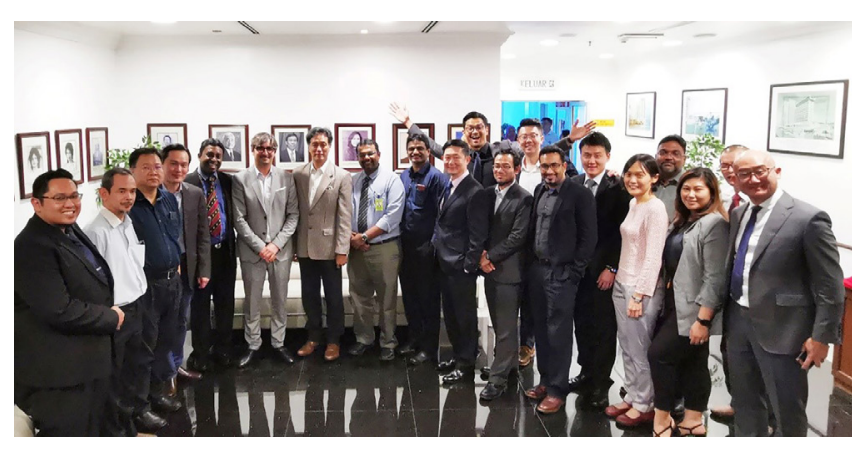

Figure 6 Participants of first Malaysia uniportal masterclass.

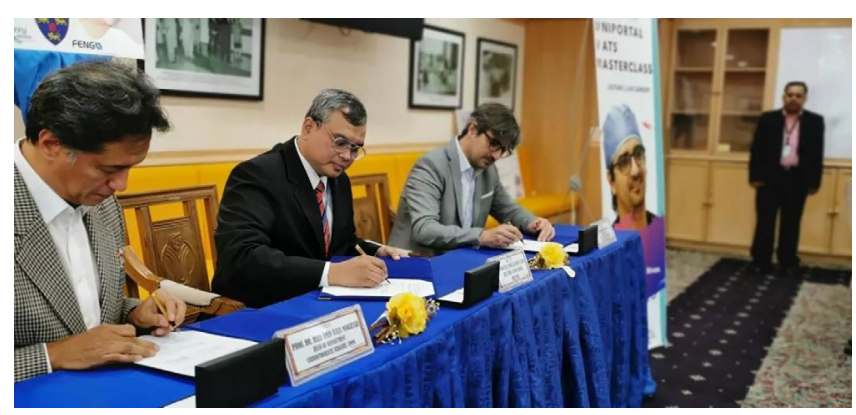

Figure $7 \mathrm{MoU}$ signing ceremony between UMMC and Dr. Diego Gonzalez Rivas. MoU, Memorandum of Understanding; UMMC, University of Malaya Medical Centre.

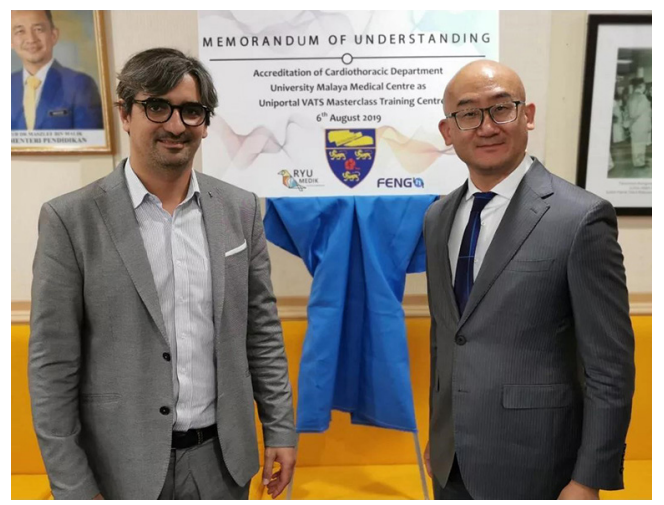

Figure 8 Dr. Diego and Mr. Godwin Lew (executive liaison of Fengh Academy of MIS). MIS, minimally invasive surgery.

GET 2019 Thoracic Surgery Chapter of FAMIS by Dr. Diego Gonzalez Rivas

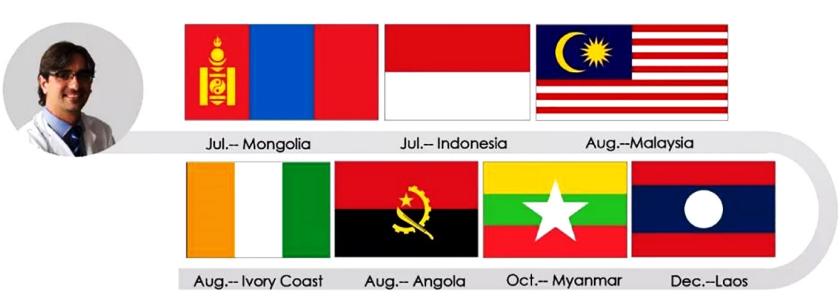

Figure 9 GET 2019 thoracic chapter of Fengh Academy of MIS. MIS, minimally invasive surgery. 


\section{Acknowledgments}

We thank University of Malaya Medical Centre (UMMC), the guest speakers and all the participants for their support to the success of the course.

Funding: None.

\section{Footnote}

Provenance and Peer Review: This article was commissioned by the editorial office, fournal of Visualized Surgery for the series "Teaching Uniportal VATS". The article has undergone external peer review.

Conflicts of Interest: All authors have completed the ICMJE uniform disclosure form (available at https://jovs. amegroups.com/article/view/10.21037/jovs.2019.12.10/ coif). The series "Teaching Uniportal VATS" was commissioned by the editorial office without any funding or sponsorship. DGR served as the unpaid Guest Editor of the series and serves as an unpaid associate Editor-in-Chief of Journal of Visualized Surgery. The authors have no other conflicts of interest to declare.

Ethical Statement: The authors are accountable for all aspects of the work in ensuring that questions related

doi: $10.21037 /$ jovs.2019.12.10

Cite this article as: Gonzalez-Rivas D, Krishnasamy S, Lew G, Zhu A. First Malaysia uniportal video-assisted thoracic surgery (VATS) masterclass. J Vis Surg 2020;6:34. to the accuracy or integrity of any part of the work are appropriately investigated and resolved. All procedures performed in studies involving human participants were in accordance with the Helsinki Declaration (as revised in 2013). Individual informed consent was obtained.

Open Access Statement: This is an Open Access article distributed in accordance with the Creative Commons Attribution-NonCommercial-NoDerivs 4.0 International License (CC BY-NC-ND 4.0), which permits the noncommercial replication and distribution of the article with the strict proviso that no changes or edits are made and the original work is properly cited (including links to both the formal publication through the relevant DOI and the license). See: https://creativecommons.org/licenses/by-nc-nd/4.0/.

\section{References}

1. Gonzalez-Rivas D, Krishnasamy S, Lew G, et al. Video documentation of the live surgery during the masterclass. Asvide 2020;7:068. Available online: http:// www.asvide.com/watch/33107

2. Gonzalez-Rivas D, Krishnasamy S, Lew G, et al. Iatrogenic left main bronchus rupture after intubation repaired by uniportal VATS. Asvide 2020;7:069. Available online: http://www.asvide.com/watch/33108 